\title{
Hydrosonography in the evaluation of colorectal polyps
}

\author{
Ung-Paw Ling, Jia-Yuh Chen, Chi-Jou Hwang, Chin-Kun Lin, Mei-Hwei Chang
}

\begin{abstract}
Prewarmed saline enemas and transabdominal ultrasound (hydrosonography) were used to evaluate 17 consecutive children with rectal bleeding before colonoscopy. Twelve patients with polyps were identified (10 by ultrasound, 10 by endoscopy): these included multiple hyperplastic polyps (1), multiple polyps (1), solitary polyps (9), and pseudopolyps (1). Ultrasound identified 11 polyps in 10 patients, missing two patients with small polyps less than $0.5 \mathrm{~cm}$ in diameter. The polyps were hyperechoic ovoid masses fixed to the colonic wall, with a stalk (7), submucosal infolding (5), and intraluminal floating (5). There was one false positive. Colonoscopy was refused by one patient and failed to reach beyond the distal sigmoid in another following previous surgery for malrotation. Colonoscopy was superior in identifying finer mucosal detail (colitis, ulcers, proctitis, anal fissure) and in detecting smaller polyps (sessile polyps, hyperplastic polyps). Hydrosonography of the colon is a simple, relatively non-invasive procedure that provides an alternative, radiationfree examination of the whole colon before colonoscopy. It is complementary to colonoscopy in the management of rectal bleeding in children.

(Arch Dis Child 1995; 73: 70-73)
\end{abstract}

Keywords: hydrosonography, juvenile colorectal polyps.

Chung Shan Medical College Hospital, Taichung, Department of Paediatrics

U-P Ling

J-Y Chen

Department of Colorectal Surgery C-J Hwang

Department of Medicine

$\mathrm{C}-\mathrm{K}$ Lin

Department of Paediatrics, National Taiwan University Tospital, Taipei, Taiwan, Republic of China

M-H Chang

Correspondence and reprint requests to: Dr Ung-Paw Ling, Department of of Paediatrics, Chung Shan Medical College Hospital, 1, Taichung Kang Road, Taichung, Taiwan, Republic of China. Accepted 30 January 1995
Juvenile polyps are relatively common, affecting $1 \cdot 1 \%$ of preschool and school aged children. ${ }^{1}$ They occur in isolated, multiple, and/or familial forms. The majority are between 1 to $2 \mathrm{~cm}$ in diameter, $72-77 \%$ greater than $1 \mathrm{~cm}^{23} ; 60-97 \%$ are pedunculated..$^{3-5}$ Mazier et al proposed that polyps approaching $1 \mathrm{~cm}$ in diameter had a tendency to prolapse from the colonic wall, drawing out a pedicle of intestinal mucosa. ${ }^{3}$ Loss of pedicle integrity would result in spontaneous expulsion of polyps, an incidence of 5 to $12 \%$ observed over several years. ${ }^{6-9}$ Furthermore, in series with adequate follow up, there was between $17 \%$ to $25 \%$ recurrence of juvenile polyps. 5810

In children suspected of juvenile polyps, diagnostic evaluation usually includes barium enema and sigmoidoscopy ${ }^{2-811}$ or colonoscopy. ${ }^{9} 1012-16$ When combined with double contrast barium enema, colonoscopy is a highly accurate means of evaluating colonic lesions in adults. ${ }^{17-21}$ Recent pioneering work by Limberg showed that hydrosonography of the colon was almost as sensitive as colonoscopy in detecting colonic polyps larger than $0.7 \mathrm{~cm}$ in diameter, including those located proximal to the sigmoid colon. ${ }^{22} 23$ It might therefore be appropriate to apply sonography in pre-endoscopic examination of the whole colon in children suspected of colorectal polyps. ${ }^{24}$

\section{Subjects and methods}

From January 1991 to October 1994, children with rectal bleeding were evaluated with hydrosonographic evaluation of the whole colon followed by colonoscopy. Seventeen children, mean age $4 \cdot 7$ years (range $1 \cdot 3-10 \cdot 0$ years), were examined by the same sonographer (U-PL). Bowel preparation before hydrosonography included magnesium citrate syrup $(30 \mathrm{ml} /$ year of age, maximum $300 \mathrm{ml}$ ), bisacodyl ( $5 \mathrm{mg}$ for child less $10 \mathrm{~kg}, 10 \mathrm{mg}$ otherwise), and dimethicone ( $4 \mathrm{mg} / \mathrm{kg}$ ) by mouth 20 to 24 hours before the procedure. Clear liquid intake was encouraged over this period, for older children, $500 \mathrm{ml}$ or more over the first two to three hours. Each patient received bisacodyl (10 $\mathrm{mg} /$ dose) rectal suppositories twice, at eight and four hours before sonography. Except for the older children who could cooperate, most patients $(n=13)$ were mildly sedated with rectal quinalbarbitone or chloral hydrate.

Prewarmed normal saline was used for retrograde enemas. After initial filling of the rectum, the patient was supported in the sitting position while saline was infused to obtain optimal filling of the sigmoid. ${ }^{14}$ During sonography, postural changes were required to obtain maximal saline filling of each segment of interest and to circumvent the presence of air. The rectum was examined with the patient in supine and right lateral decubitus positions while the transverse colon was examined in the supine and right or left lateral decubitus position with addition of cross table scanning. The colonic flexures were examined with subcostal and lateral intercostal scanning. The ascending and descending colon could be readily evaluated in the supine position. Using longitudinal and transverse scans, repeated transabdominal sonographic evaluation of each segment of interest was performed with a $5 \mathrm{MHz}$ transducer (Aloka SSD-630, Japan) with intermittent video recording.

The presence of colonic polyps, that is any lesion raised above the surface of the mucosa, was identified sonographically by evidence of an intraluminal ovoid, homogenously 
echogenic mass that is relatively fixed to the colonic wall. Small lesions, especially those less than $0.7 \mathrm{~cm}$, could be mistaken for colonic haustra. Circumferential orientation of the haustra on transverse scan and elongation or convergence of two or more opposing folds on longitudinal scan usually differentiated them. Identification of a stalk or infolding of the submucosa into the pedicle assisted in this aspect of investigation (fig 1).

Small polyps need to be differentiated from adherent faecal masses, which are otherwise seen as free floating, hyperechoic intraluminal masses with irregular shape and outline. This includes movement observed during postural changes, percutaneous compression, further saline infusion on subsequent scanning, and presence of air microbubbles. Colonoscopy was performed within a week of hydrosonography. When a polyp was identified, polypectomy and histological examination were performed.

\section{Results}

The normal colon appears as an echo free tubular lumen 1.5 to $5 \mathrm{~cm}$ in diameter, with frequent echogenic sawtooth structures projecting into the lumen (colonic haustra). In the rectum, two to four rectal valves of Houston could be identified. Typically, these could be traced on their circumferential span on the rectal wall.

Whenever pockets of gas or accumulated faecal material prevented adequate visualisation of a particular loop of bowel, postural changes and/or further saline infusion usually permitted satisfactory sonographic examination. Particulate faecal residues, accumulating in the right colon, were observed in 13 of 17 patients $(76 \cdot 5 \%)$. None the less, the colonic wall could be readily outlined. Further infusion

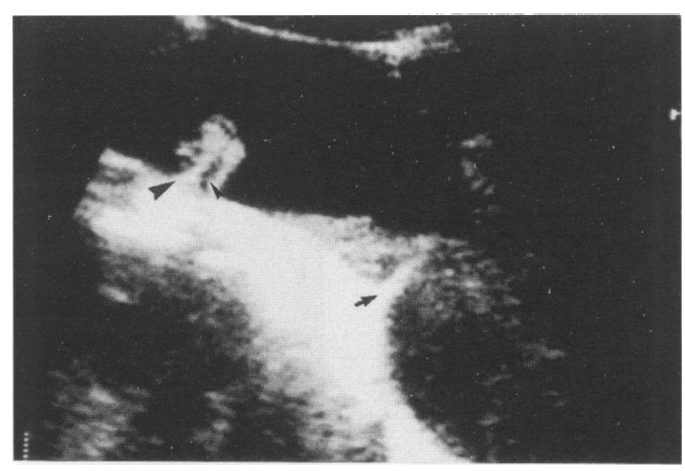

Figure 1 Hydrosonographic finding of a echogenic polyp (large arrow head) on the posterior wall of the proximal rectum with central anechoic core (small arrow head) corresponding to infolding of submucosa. Rectal valve of Houston (arrow).

of saline to decrease the concentration of faecal residues always improved the clarity of colonic wall identification. After initially learning how to differentiate colonic haustra, adherent faecal masses, the ileocaecal valve and the rectal valves of Houston from polyps, a satisfactory evaluation of the whole colon could be completed within 30 minutes.

Seventeen children underwent hydrosonographic investigation for rectal bleeding (table). It was well tolerated and there were no side effects. Two of them received single contrast barium enemas (patient 1 and 2). Barium enema failed to demonstrate a large splenic flexure polyp, measuring $2.5 \mathrm{~cm}$ in diameter, in patient 1 while patient 2 had an indeterminate rectal filling defect. Patient 3 had undergone barium enema and colonoscopic polypectomy six months previously and suffered recurrent bleeding for one month. Preendoscopic hydrosonography determined with certainty the presence of colorectal polyps.

Colonoscopy and hydrosonography were complementary in several patients. Patient

Clinical data of 17 patients evaluated with colon hydrosonography including 11 patients with juvenile polyps and one with pseudopolyps

\begin{tabular}{|c|c|c|c|c|c|c|}
\hline $\begin{array}{l}\text { Patient } \\
\text { No }\end{array}$ & Sex & $\begin{array}{l}\text { Age } \\
\text { (years) }\end{array}$ & $\begin{array}{l}\text { Duration } \\
\text { of } \\
\text { bleeding }\end{array}$ & Hydrosonography & Colonoscopy & Pathology \\
\hline 1 & $\mathbf{M}$ & $2 \cdot 3$ & $1 y^{\star}$ & $\begin{array}{l}2 \times 2.5 \mathrm{~cm} \text { polyp in descending colon. Echo } \\
\text { follow up }\end{array}$ & Large polyp in descending colon & JP \\
\hline $\begin{array}{l}2 \\
3\end{array}$ & $\begin{array}{l}\mathrm{F} \\
\mathrm{F}\end{array}$ & $\begin{array}{l}4 \cdot 0 \\
5 \cdot 5\end{array}$ & $\begin{array}{l}1 \mathrm{y}^{\star} \\
1 \mathrm{~m} \dagger\end{array}$ & $\begin{array}{l}1.1 \times 2.5 \mathrm{~cm} \text { polyp on posterior wall of rectum } \\
1.8 \times 1.3 \mathrm{~cm} \text { polyp on posterior wall of rectum }\end{array}$ & $\begin{array}{l}\text { Rectal polyp } \\
\text { Rectal polyp }\end{array}$ & $\begin{array}{l}\text { JP } \\
\text { JP }\end{array}$ \\
\hline 4 & $\mathbf{M}$ & $7 \cdot 0$ & $2 y$ & $\begin{array}{l}0.8 \times 0.6 \mathrm{~cm} \text { polyp on anterior wall of distal } \\
\text { rectum }\end{array}$ & Rectal polyp & $\mathrm{JP}$ \\
\hline 5 & $\mathbf{M}$ & $3 \cdot 0$ & $6 \mathrm{~m}$ & $\begin{array}{l}1.3 \times 0.8 \mathrm{~cm} \text { polyp on anterior wall of proxi- } \\
\text { mal rectum }\end{array}$ & $\begin{array}{l}\text { Refused colonoscopy. Echo follow } \\
\text { up }\end{array}$ & NA \\
\hline 6 & $\mathbf{M}$ & $4 \cdot 0$ & $2 \mathrm{~m}$ & $\begin{array}{l}2 \text { polyps: } 1.0 \times 0.8 \mathrm{~cm} \text { in the rectum and } \\
0.6 \times 0.4 \mathrm{~cm} \text { in the sigmoid }\end{array}$ & $\begin{array}{l}3 \text { polyps: rectum, sigmoid, hepatic } \\
\text { flexure }(0.3 \times 0.4 \mathrm{~cm})\end{array}$ & $\mathrm{JP}$ \\
\hline 7 & $\mathbf{F}$ & $5 \cdot 0$ & $1 \mathrm{~m}$ & $\begin{array}{l}0.9 \times 0.8 \mathrm{~cm} \text { polyp on anterior wall of distal } \\
\text { rectum }\end{array}$ & Rectal polyp & JP \\
\hline $\begin{array}{l}8 \\
9\end{array}$ & $\begin{array}{l}\mathbf{F} \\
\mathbf{M}\end{array}$ & $\begin{array}{l}4 \cdot 0 \\
7 \cdot 0\end{array}$ & $\begin{array}{l}1 \mathrm{y} \\
1 \mathrm{w}\end{array}$ & $\begin{array}{l}2.3 \times 1.8 \mathrm{~cm} \text { polyp in descending colon } \\
1.6 \times 1.5 \mathrm{~cm} \text { polyp on posterior wall of distal } \\
\text { rectum }\end{array}$ & $\begin{array}{l}\text { Failed } \neq \\
\text { Rectal polyp }\end{array}$ & $\begin{array}{l}\text { NA } \\
\text { JP }\end{array}$ \\
\hline $\begin{array}{l}10 \\
11\end{array}$ & $\begin{array}{l}\mathbf{M} \\
\mathbf{M}\end{array}$ & $\begin{array}{l}6 \cdot 0 \\
0 \cdot 7\end{array}$ & $\begin{array}{l}3 \mathrm{w} \\
1 \mathrm{~m}\end{array}$ & $\begin{array}{l}\text { No finding } \\
\text { No finding }\end{array}$ & $\begin{array}{l}\text { Flat sessile polyp less than } 0.5 \mathrm{~cm} \\
\text { Multiple hyperplastic polyps in } \\
\text { ascending colon }\end{array}$ & $\begin{array}{l}\text { JP } \\
\text { NA }\end{array}$ \\
\hline 12 & $\mathbf{M}$ & $5 \cdot 5$ & $2 \mathrm{w}$ & No finding & $\begin{array}{l}\text { Multiple small ulcers from caecum } \\
\text { to descending colon }\end{array}$ & NSI \\
\hline $\begin{array}{l}13 \\
14 \\
15 \\
16 \\
17\end{array}$ & $\begin{array}{l}\mathbf{M} \\
\mathrm{F} \\
\mathbf{M} \\
\mathbf{M} \\
\mathbf{M}\end{array}$ & $\begin{array}{r}5 \cdot 0 \\
10 \cdot 0 \\
5 \cdot 4 \\
2 \cdot 0 \\
5 \cdot 0\end{array}$ & $\begin{array}{l}1 \mathrm{w} \\
1 \mathrm{~m} \\
5 \mathrm{y} \\
1.5 \mathrm{y} \\
2 \mathrm{w}\end{array}$ & $\begin{array}{l}\text { No finding } \\
\text { No finding } \\
\text { Enlarged rectum } \\
\text { Small polyp } 0.5 \times 0.5 \mathrm{~cm} \text { in descending colon } \\
0.8 \mathrm{~cm} \text { polyp with hazy margins in mid-rec- } \\
\text { tum }\end{array}$ & $\begin{array}{l}\text { Proctitis } \\
\text { No finding } \\
\text { Anal fissure } \\
\text { No finding } \\
\text { Pseudomembranous colitis, colonic } \\
\quad \text { ulcers, rectal pseudopolyps }\end{array}$ & $\begin{array}{l}\text { NSI } \\
\text { NA } \\
\text { NA } \\
\text { NA } \\
\text { NSI }\end{array}$ \\
\hline
\end{tabular}

^Barium enema showed no polyps in patient 1 and a rectal filling defect in patient 2.

†Recurrent bleeding with previous barium enema and colonoscopic polypectomy in patient 3.

$\neq$ Colonoscopy failed in patient 8 with previous operation for malrotation.

$\mathrm{JP}=$ juvenile polyps; $\mathrm{NA}=$ not available; $\mathrm{NSI}=$ non-specific inflammation; $y=y e a r s ; m=$ months; $w=w e e k s$. 


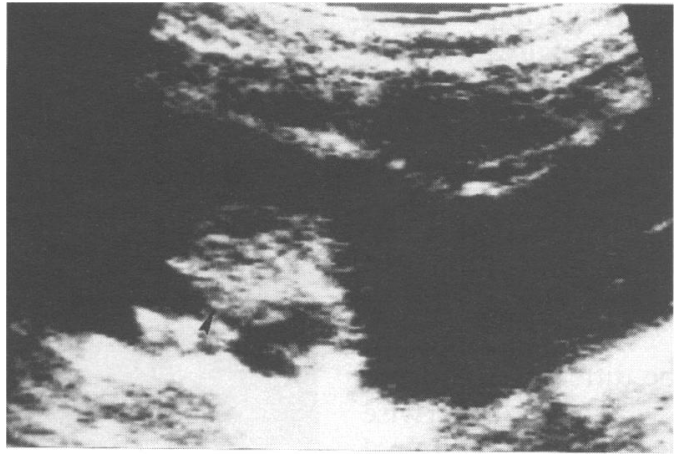

Figure 2 Hydrosonographic finding of patient 8 who had an aborted colonoscopy due to previous surgery for malrotation. A hyperechoic ovoid mass (arrow head) with pedicle is present, floating within the lumen.

5 had a pedunculated rectal polyp on sonography but refused therapeutic colonoscopy and opted for ultrasound follow up. Patient 8, who had surgery at birth for malrotation, had a large polyp in the descending colon detected by ultrasound (fig 2). Colonoscopy failed to reach beyond the distal sigmoid and was aborted. Ultrasound missed one small polyp $(0.3 \times 0.4 \mathrm{~cm}$ in the transverse colon) in patient 6 with multiple polyps. Hydrosonography also failed to detect a small, flat sessile polyp raised less than $0.5 \mathrm{~cm}$ above the mucosal surface in patient 10 and multiple hyperlastic polyps in the ascending colon in patient 11 (table). In patient 17, rectal bleeding occurred for two weeks after four weeks of antibiotic treatment for diarrhoea. Colonoscopy revealed pseudomembranous colitis with a polypoid inflammatory mass in the rectum and scattered ulcers in the sigmoid and descending colon.

Overall, hydrosonography was able to detect with certainty the presence of polyps in 11 of the 17 patients, with an identifiable stalk (7), submucosal infolding (5), and floating within the lumen (5). Two patients, in whom colonoscopy failed or was refused, received further sonographic follow up. Colonoscope derived histological specimens were available from eight patients with juvenile polyps, showing cystic dilatation of glands lined by mucus secreting tall columnar epithelium with goblet cells and loose, oedematous stroma.

\section{Discussion}

Rectal bleeding is a common symptom in children, which may be alarming. Causes include abrasion, trauma, anal fissure, constipation, infectious colitis, allergic enterocolitis, or potentially life threatening events such as intussusception, Meckel's diverticulum, volvulus, or blood dyscrasias. Clinical history, physical examination, and laboratory investigation usually differentiate these. Imaging procedures may include sonography, barium enema, sigmoidoscopy or colonoscopy, technetium-99m pertechnetate scan, and angiography. However, for colorectal polyps, the most common cause of painless, intermittent rectal bleeding in childhood, barium enema and colonoscopy are usually performed.
Conventional transabdominal ultrasound cannot detect colonic polyps, due to intraluminal gas and absence of wall infiltration. The exception is when there is incidental bowel loop distension by intraluminal faecal fluid. $^{25}$ Water enema was first proposed to overcome intraluminal gas during pelvic sonography. ${ }^{26}$ In recent years, hydrosonography has been applied to the diagnosis of inflammatory bowel disease, colonic tumours, and colorectal polyps. ${ }^{22-24} 27-29$

This study confirms the usefulness of hydrosonography in evaluating colonic polyps in children. It is a simple procedure performed in outpatients or as a day case. Radiation-free evaluation of the whole colon is possible before resorting to more invasive procedure such as sigmoidoscopy or colonoscopy. It provides definite precolonoscopic detection and localisation of polyps in a manner similar to colonoscopy (a sensitivity of $97 \%$ for polyps over $0.7 \mathrm{~cm}$ in diameter). ${ }^{22} 23$ There is also minimal discomfort and we found no side effects. Understandably, there is greater acceptance by parents and patients.

While superior in delineating fine mucosal details and detecting smaller polyps, colonoscopy cannot be used as the 'gold standard' for polyp detection. It has been reported to miss $9-12 \%$ of colonic polyps. ${ }^{17} 19-2130$ Polyps larger than $2 \mathrm{~cm}$ in diameter have been missed by colonoscopy in children. ${ }^{31} 32$ This could be due to a large fold obscuring the lesion, bleeding, polyps submerged in a faecal fluid lake, redundant sigmoid or transverse colon, inadequate colon preparation, or the area could not be reached for technical reasons. In addition, the right side of the colon and caecum cannot be seen at colonoscopy in 10 to $30 \%$ of patients. 1013143334

The advantage of precolonoscopic detection and localisation is therefore considerable, permitting colonoscopy to become a highly accurate means of examination for colorectal polyps. Hydrosonography could play an important part in this respect. Double and single contrast radiology miss less than $10 \%$ of polyps over $1 \mathrm{~cm}$ in diameter, but up to $29 \%$ and $30-45 \%$ of smaller polyps, respectively, in adults $^{17-21}$ and $27 \%{ }^{13}$ and $15-39 \%, 91012$ respectively, in children. Our experience with hydrosonography showed that even with colon preparation, considerable faecal material accumulates in the right colon. This could account for the reduced radiological detection of polyps in the proximal colon. ${ }^{30} 35$ In addition, it is difficult to obtain stringent adherence to a colon preparation regimen for barium enema in children. ${ }^{36} 37$

Recent reports in children indicate that colonoscopy is superior to single contrast barium enema 9101216 or sigmoidoscopy combined with double contrast enema ${ }^{11} 1315$ in detecting polyps. Colonoscopy identified more plural polyps (more than $50 \%)^{1011}$ and more polyps located proximal to the sigmoid (40 to $60 \%)^{101131}$ than in previous reports of children using sigmoidoscopy combined with single contrast barium enema $(14-26 \%, 10-26 \%$, respectively) ${ }^{36838}$ or double contrast barium 
enema (14-27\%, 8.5-9\%, respectively). 571139 Whether hydrosonography is superior to barium enema in precolonoscopic evaluation of colorectal polyps in children deserves further study. Interestingly, Walter et al recently reported the diagnosis of a large juvenile polyps by hydrosonography in a 4 year old boy who had a non-diagnostic barium enema and colonoscopy before a second colonoscopy. ${ }^{32}$

Hydrosonographic colonic imaging is a simple, radiation-free procedure that could play a major part in the evaluation and follow up of children with rectal bleeding.

1 Helwig EB. Adenomas of the large intestine in children. $A m$ 7 Dis Child 1946; 72: 289-95.

2 Mazier WP, MacKeigan JM, Billingham RP, Dignan RD. Juvenile polyps of the colon and rectum. Surg Gynecol Obstet 1982; 154: 829-32.

3 Mazier WP, Bowman HE, Sun KM, Muldoon JP. Juvenile polyps of the colon and rectum. Dis Colon Rectum 1974 17: 523-7.

4 Turrel R, Maynard ADL. Adenomas of the rectum and colon in juvenile patients. $7 A M A 1956 ; 161: 57-60$.

5 Horrilleno EG, Eckert C. Ackerman LV. Polyps of the rectum and colon in children. Cancer 1957; 10: 1210-20.

6 Roth SI, Helwig EB. Juvenile polyps of the colon and rectum. Cancer 1963; 16: 468-79.

7 Harris JW. Polyps of the colon and rectum in children. $A m$ f Surg 1953; 86: 577-82.

8 Franklin R, McSwain B. Juvenile polyps of the colon and rectum. Ann Surg 1972; 175: 887-91.

9 Nagasaki A, Yamanaka K, Toyohara T, Ohgami H, Aoki T, Sueishi K Management of colorectal polyps in children. Acta Paediatr $\mathcal{F} p$ (overseas edition) 1993; 35: 32-5.

10 Cynamon HA, Milov DE, Andres JM. Diagnosis and management of colonic polyps in children. $\mathcal{F}$ Pediatr $1989 ; 114$ : 593-6.

11 Mestre JR. The changing pattern of juvenile polyps. Am $f$ Gastroenterol 1986; 81: 312-4.

12 Habr-Gama A, Alves PRA, Gama-Rodrigues JJ, et al. Pediatric colonoscopy. Dis Col Rectum 1979; 22: 530-5.

13 Hassall E, Barclay GN, Ament ME. Colonoscopy in childhood Pediatrics 1984; 73: 594-9.

14 Thapa BR, Mehta S. Diagnostic and therapeutic colonoscopy in children: experience from a pediatric gastroenterology centre in India. Indian Pediatr 1991; 28: 383-9.

15 Euler AR, Seibert J. The role of sigmoidoscopy, radiographs, and colonoscopy in the diagnostic evaluation of pediatric age patients with suspected juvenile polyps. f Pediatr Surg 1981; 16: 500-2.

16 Tam PKH, Saing H. Pediatric surgeons can and should perform colonoscopy. F Pediatr Surg 1987; 22: 332-4.

17 Fork FT. Double contrast enema and colonoscopy in polyp detection. Gut 1981; 22: 971-7.
18 Ott DJ, Chen YM, Gelfand DW, et al. Single-contrast vs double-contrast barium enema in the detection of colonic polyps. $A \mathscr{T} R$ 1986; 146: 993-6.

19 Thoeni RF, Menuck L. Comparison of barium enema and colonoscopy in the detection of small colonic polyps. Radiology 1977; 124: 631-5.

20 Laufer I, Smith NC, Mullens JE. The radiological demonstration of colorectal polyps undetected by endoscopy. Gastroenterology 1976; 70: 167-70.

21 Ott DJ, Scharling ES, Chen YM, et al. Barium enema examination: sensitivity in detecting colonic polyps and carcinomas. South Med f 1989; 82: 197-200.

22 Limberg B. Diagnosis of large bowel tumors by colonic sonography. Lancet 1990; 335: 144-6.

23 Limberg B. Diagnosis and staging of colonic tumors by conventional abdominal sonography as compared with conventional abdominal sonography as compared with hydroco

24 Nagita A, Ammemoto K, Yoden A, et al. Ultrasonographic diagnosis of juvenile colonic polyps. $\mathcal{F}$ Pediatr 1994; 124 535-40.

25 Walecki JK, Hales Ed, Chung EB, Laster HD. Ultrasound contribution to diagnosis of Peutz-Jeghers syndrome. Pediatr Radiol 1984; 14: 62-4.

26 Rubin C, Kurtz AB, Goldberg BB. Water enema: a new ultrasound technique in defining pelvic anatomy. fournal of Clinical Ultrasound 1978; 6: 28-33.

27 Limberg B. Diagnosis of inflammatory and tumorous changes of the large intestine using colonic sonography. Dtsch Med Wochenschr 1986; 111: 1273-6.

28 Limberg B. Diagnosis of inflammatory and neoplastic colonic disease by sonography. $\mathcal{f}$ Clin Gastroenterol 1987; 9: 607-11.

29 Limberg B. Diagnosis of tumors of the large intestine by colonic ultrasound. Ultraschall Med 1990; 11: 127-31.

30 Gelfand DW, Chen YM, Ott DJ. Colonic cleansing for radiologic detection of neoplasia: efficacy of the magnesium citrate-castor oil-cleansing enema regimen. $A \mathscr{f} R$ 1988; 151: 705-8.

31 Latt TT, Nicholl R, Domizio P, Walker-Smith JA, Williams CB. Rectal bleeding and polyps. Arch Dis Child 1993; 69: 144-7.

32 Walter DF, Govil S, Korula A, William RR, Chandy G. Peduculated colonic polyp diagnosed by colonic sonography. Pediatr Radiol 1992; 22: 148-9.

33 Williams CB, Laage NJ, Campbell CA, et al. Total colonoscopy in children. Arch Dis Child 1982; 57: 49-53.

34 Plucnar BJ. Colonoscopy in infancy and childhood with special regard to patient preparation and examination special regard to patient preparation

35 Laufer I. The double-contrast enema: myth and misconceptions. Gastrointestinal Radiology 1976; 70: 19-31.

36 Lee JMH, Tam PKH, Saing H. Whole-gut irrigation in infants and young children. Dis Colon Rectum 1986; 29: 252-4.

37 Postuma R. Whole bowel irrigation in pediatric patients f Pediatr Surg 1982; 17: 350-2.

38 Gordon DL, Hallenbeck GA, Dockerty MB, Kennedy RLJ Jackman RJ. Polyps of the colon in children. Arch Surg 1957; 75: 90-5.

39 Slim MS, Alameddine A, Nassar V, Mishalany H. Rectal and colonic polyps in childhood. American fournal of Proctology 1977; 28: 27-32. 